\title{
Hydrogen molecules and hydrogen-related defects in crystalline silicon
}

\author{
N. Fukata, S. Sasaki, and K. Murakami \\ Institute of Materials Science, University of Tsukuba, Tennoudai 1-1-1, Tsukuba, Ibaraki 305, Japan \\ K. Ishioka, K. G. Nakamura, and M. Kitajima \\ National Research Institute for Metals, Sengen 1-2-1, Tsukuba, Ibaraki 305, Japan \\ S. Fujimura and J. Kikuchi \\ Process Development Division, Fujitsu Ltd., Kawasaki, Kanagawa 211, Japan \\ H. Haneda \\ National Institute for Research in Inorganic Materials, Namiki 1-1, Tsukuba, Ibaraki 305, Japan
}

(Received 31 January 1997; revised manuscript received 3 June 1997)

\begin{abstract}
We have found that hydrogen exists in molecular form in crystalline silicon treated with hydrogen atoms in the downstream of a hydrogen plasma. The vibrational Raman line of hydrogen molecules is observed at $4158 \mathrm{~cm}^{-1}$ for silicon samples hydrogenated between 180 and $500{ }^{\circ} \mathrm{C}$. The assignment of the Raman line is confirmed by its isotope shift to $2990 \mathrm{~cm}^{-1}$ for silicon treated with deuterium atoms. The Raman intensity has a maximum for hydrogenation at $400{ }^{\circ} \mathrm{C}$. The vibrational Raman line of the hydrogen molecules is broad and asymmetric. It consists of at least two components, possibly arising from hydrogen molecules in different occupation sites in crystalline silicon. The rotational Raman line of hydrogen molecules is observed at $590 \mathrm{~cm}^{-1}$. The Raman band of Si-H stretching is observed for hydrogenation temperatures between 100 and $500{ }^{\circ} \mathrm{C}$ and the intensity has a maximum for hydrogenation at $250^{\circ} \mathrm{C}$. [S0163-1829(97)09235-7]
\end{abstract}

\section{INTRODUCTION}

Hydrogen in semiconductors has been examined extensively in various experimental and theoretical studies, which indicate there are several configurations of hydrogen in crystalline silicon. Hydrogen introduced in silicon terminates dangling bonds on the surface, and passivates deep-level impurities, as well as shallow acceptors and donors in the bulk. ${ }^{1}$ An infrared-absorption experiment has shown that hydrogen introduced in to $p$ - or $n$-type silicon forms complexes with acceptor or donor atoms. ${ }^{2}$ Other experimental results and theoretical calculations have suggested that $\{111\}$ platelets $^{3-8}$ and a metastable diatomic hydrogen complex ${ }^{9-11}$ are formed in heavily doped $n$-type silicon.

Recent theoretical calculations have suggested that the hydrogen molecule is stable in crystalline silicon. ${ }^{10-15}$ Chadi and co-workers have performed a calculation of the total energies and defect levels of various hydrogen-related defects using the $a b$ initio pseudopotential method, and have suggested that the hydrogen molecule is stable at Si tetrahedral interstitial sites with its axis along a $\langle 111\rangle$ or a $\langle 100\rangle$ direction. ${ }^{10,11}$ The bond length of a hydrogen molecule at the tetrahedral interstitial site is calculated to be $0.78 \AA$, about $0.03 \AA$ longer than that in the gas phase. Van de Walle and co-workers have calculated the energy of hydrogen interacting with bulk silicon and defects in the silicon lattice, using density-functional theory in the local-density approximation and $a b$ initio pseudopotentials. ${ }^{12,13}$ They have predicted that a hydrogen molecule is stable at the tetrahedral interstitial site oriented along a $\langle 100\rangle$ direction.

In hydrogenated amorphous silicon, hydrogen molecules are observed using infrared absorption ${ }^{16}$ and nuclear mag- netic resonance. ${ }^{17}$ In crystalline silicon, there are several experimental studies suggesting the existence of hydrogen molecules. ${ }^{18-21}$ However, all the results are indirect or controversial. Stutzmann and co-workers have studied the transformation of deuterium in $p$-type silicon using thermal desorption, Raman, and infrared-absorption spectroscopy. They inferred the existence of interstitial $\mathrm{D}_{2}$ molecules after dissociation of $B-D$ complexes by thermal annealing at $250{ }^{\circ} \mathrm{C}$ for $1 \mathrm{~h},{ }^{18}$ although they did not detect any Raman spectrum associated with interstitial $\mathrm{D}_{2}$ molecules. Johnson and Herring reported an immobile form of nonatomic hydrogen, which they have attributed to molecular hydrogen based on their secondary-ion mass spectrometry measurements. ${ }^{19}$ Stallinga et al. have performed electron-paramagneticresonance experiments on silicon annealed at $250{ }^{\circ} \mathrm{C}$ for 30 min after implantation with hydrogen and deuterium. ${ }^{20}$ They observed a trigonally symmetric defect center labeled NL52, which they associated with a negatively charged hydrogen molecule. However, they have not reported any isotope effect on implantation with deuterium ${ }^{20}$ and Brower et al. have reported no level associated with negatively charged hydrogen molecules. ${ }^{21}$

Recently, we have confirmed the existence of hydrogen molecules in crystalline silicon by detecting their vibrational and rotational Raman lines in heavily doped $n$-type crystalline silicon treated with hydrogen atoms. ${ }^{22-24}$ Hydrogen molecules have also been seen in GaAs. ${ }^{25}$ In this paper, we report a detailed study on the hydrogenation-temperature dependence of the formation of hydrogen molecules by means of Raman measurements. Raman spectra of hydrogen molecules are observed not in only $n$-type silicon with $\mathrm{P}^{+}$ implantation but also in $p$-type silicon without implantation. 
The vibrational Raman band assigned to hydrogen molecules consists of at least two components, plausibly corresponding to two different occupation sites in crystalline silicon. The formation of hydrogen molecules is discussed in comparison with that of other hydrogen-related defects such as $\mathrm{Si}-\mathrm{H}$ bonds and $\{111\}$ platelets.

\section{EXPERIMENTAL METHODS}

We used $p$-type [100] floating zone (FZ) Si (80-100 $\Omega \mathrm{cm}$ ) wafers for our samples. Some of the samples were implanted with $\mathrm{P}^{+}$(phosphorus ions) at a dose of $5 \times 10^{14} / \mathrm{cm}^{2}$ at an energy of $50 \mathrm{keV}$ to obtain heavily doped $n$-type silicon. All the implanted $\mathrm{P}$ impurities were electrically activated by furnace annealing at $900{ }^{\circ} \mathrm{C}$ for $30 \mathrm{~min}$ in an atmosphere of flowing $\mathrm{N}_{2}$ gas. Other samples were used without $\mathrm{P}^{+}$implantation to study the effect of ion implantation and thermal annealing.

A hydrogen atom treatment (HAT) was performed on all the silicon samples using a remote downstream flux of hydrogen atoms from an $\mathrm{H}_{2}$ plasma for $3 \mathrm{~h}$. The samples were placed in the quartz tube $60 \mathrm{~cm}$ from the plasma to suppress damage from the activated species. $\mathrm{H}_{2} \mathrm{O}$ gas $(0.05$ Torr) was added to $\mathrm{H}_{2}$ gas ( 0.95 Torr) to increase the amount of hydrogen atoms at the silicon surface. We also performed deuterium atom treatments (DAT) by using $\mathrm{D}_{2}$ and $\mathrm{D}_{2} \mathrm{O}$ instead of $\mathrm{H}_{2}$ and $\mathrm{H}_{2} \mathrm{O}$, respectively. The substrate temperature during hydrogenation was measured accurately by interference using an infrared-laser $\left(\operatorname{In}_{x} \mathrm{Ga}_{1-x} \mathrm{AsP} ; \lambda=1310 \mathrm{~nm}\right)$ with both surfaces of the wafers mirror-polished, because conventional thermocouples react with hydrogen atoms and their use leads to overestimation of the sample temperature. The substrate temperature during HAT was controlled to an accuracy of $\pm 2.5^{\circ} \mathrm{C}$. Details of the method and hydrogenation conditions have been reported elsewhere. ${ }^{26,27}$

Depth profiles of hydrogen in the sample after HAT and DAT were obtained by means of secondary-ion-mass spectroscopy (SIMS) measurements using $\mathrm{Cs}^{+}$ion beams with a CAMECA IMS $4 f$ system. The total amount of hydrogen is greatest for hydrogenation at $400{ }^{\circ} \mathrm{C}$. For hydrogenation above $600{ }^{\circ} \mathrm{C}$ and below $100{ }^{\circ} \mathrm{C}$ the concentration of hydrogen is comparable to the background level. This is accounted for in terms of a very large diffusion of hydrogen during the hydrogenation above $600{ }^{\circ} \mathrm{C}$ and a very low efficiency in the introduction of hydrogen in the substrate below $100^{\circ} \mathrm{C}$. Figure 1 shows typical depth profiles of hydrogen in the silicon samples without $\mathrm{P}^{+}$implantation after HAT. The concentration scale was determined by comparison with a standard sample implanted with hydrogen ions $\left(40 \mathrm{keV} \mathrm{H}_{2}{ }^{+}\right.$, $1 \times 10^{15} / \mathrm{cm}^{2}$ ). The depth profile of hydrogen has a maximum near the surface for the samples, and the penetration depth of hydrogen is larger for higher hydrogenation temperature. The profile for the samples with $\mathrm{P}^{+}$implantation is similar except for a slight shift of the concentration peak to a greater depth.

Raman scattering measurements were performed at room temperature and $90 \mathrm{~K}$. A cw argon-ion laser (Coherent Model INNOVA 70) with a wavelength of $514.5 \mathrm{~nm}$ was used as the excitation source. Scattered light, collected at $90^{\circ}$, was analyzed using a triple grating monochromator (JASCO TRS-600) with a wave-number resolution of up to

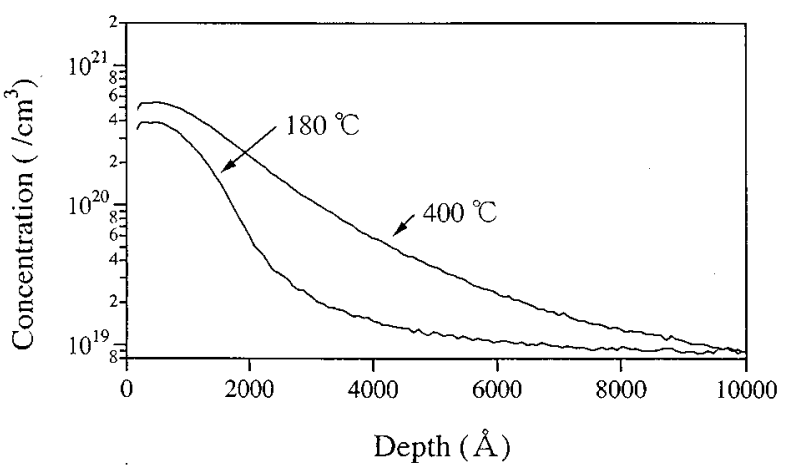

FIG. 1. Depth profiles of hydrogen for the silicon samples without $\mathrm{P}^{+}$implantation treated with hydrogen atoms at 180 and $400{ }^{\circ} \mathrm{C}$.

$0.2 \mathrm{~cm}^{-1}$ at best, and detected with a spectrometric multichannel analyzer (Princeton Instruments Inc. D/SIDA 700). Raman shifts ranging from 300 to $4300 \mathrm{~cm}^{-1}$ were measured.

\section{RESULTS}

Figure 2(a) shows a Raman spectrum for the sample with $\mathrm{P}^{+}$implantation after treatment with atomic hydrogen at $400{ }^{\circ} \mathrm{C}$ (HAT- $400{ }^{\circ} \mathrm{C}$ ). A Raman line observed at around $590 \mathrm{~cm}^{-1}$ after HAT is assigned to the $S_{0}(1)(\Delta J=2, \Delta \nu=0$, and $J=1$; here $J$ and $\nu$ are the rotational and vibrational quantum numbers, respectively) rotational line of $\mathrm{H}_{2}{ }^{22,23}$ The rotational line of para- $\mathrm{H}_{2}$ was not observed in the present study, because of the overlap with Raman lines of bulk silicon. A broad Raman band at $4158 \pm 3 \mathrm{~cm}^{-1}$ is assigned to the $Q_{1}(\Delta J=0$ and $\Delta \nu=1)$ vibrational line of the hydrogen molecule in crystalline silicon. ${ }^{22,23}$ The Raman shifts of the rotational and vibrational lines agree well with those of gaseous or solid hydrogen molecules, while the widths are much larger even compared with those in solid phase. ${ }^{28-30} \mathrm{~A}$ broad and asymmetric Raman band observed at around $2100 \mathrm{~cm}^{-1}$ is assigned to the stretching band of $\mathrm{Si}-\mathrm{H}$ bonds in crystalline silicon. ${ }^{22}$ We also measured Raman spectra for the samples without $\mathrm{P}^{+}$implantation. The rotational and vibrational Raman lines of $\mathrm{H}_{2}$ at 590 and

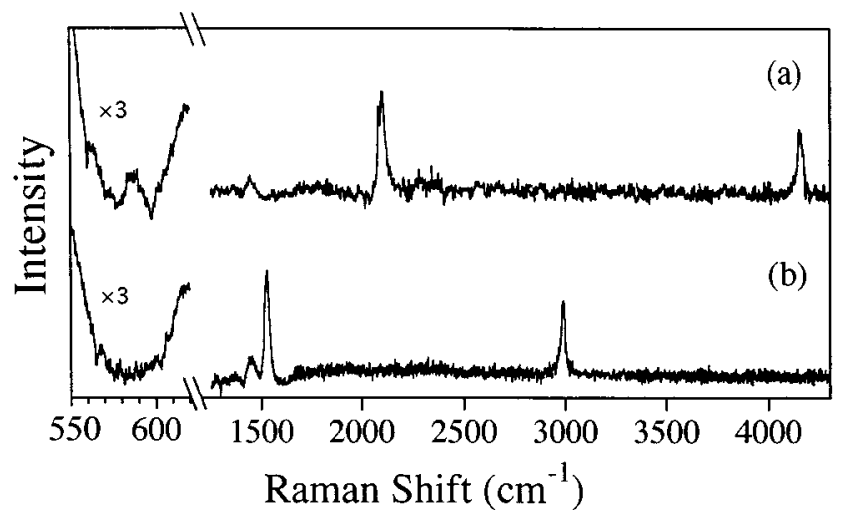

FIG. 2. Raman spectra of crystalline silicon (with $\mathrm{P}^{+}$implantation) (a) after treatment with atomic hydrogen at $400{ }^{\circ} \mathrm{C}$ and (b) after treatment with atomic deuterium at $400^{\circ} \mathrm{C}$. 


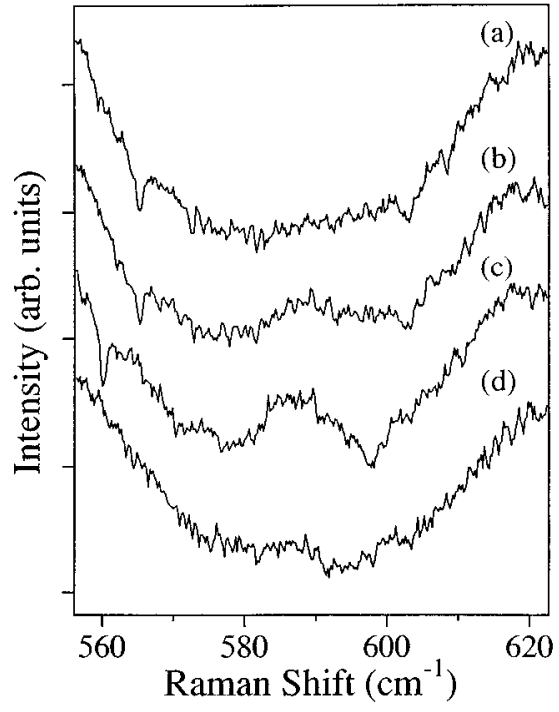

FIG. 3. The rotational Raman line of $\mathrm{H}_{2}$ in crystalline silicon (with $\mathrm{P}^{+}$implantation) treated with hydrogen atoms at various hydrogenation temperatures: (a) $250{ }^{\circ} \mathrm{C}$, (b) $350{ }^{\circ} \mathrm{C}$, (c) $400{ }^{\circ} \mathrm{C}$, and (d) $500{ }^{\circ} \mathrm{C}$.

$4158 \mathrm{~cm}^{-1}$, respectively, were observed and have almost the same line shape as those for the samples with $\mathrm{P}^{+}$implantation. This indicates that hydrogen molecules are not trapped at defects remaining after annealing the $\mathrm{P}$ ion-implanted silicon. The Raman band assigned to $\mathrm{Si}-\mathrm{H}$ stretching was also observed at around $2100 \mathrm{~cm}^{-1}$ for the sample without $\mathrm{P}^{+}$ implantation. Figure 2(b) shows a Raman spectrum of the sample treated with deuterium atoms at $400{ }^{\circ} \mathrm{C}$ (DAT$400{ }^{\circ} \mathrm{C}$ ). The Raman band at $4158 \mathrm{~cm}^{-1}$ was not observed for the DAT sample. A broad Raman line at around $2990 \mathrm{~cm}^{-1}$, which was not observed for the HAT sample, is assigned to the vibrational Raman line of $\mathrm{D}_{2}{ }^{22,23}$ This isotope shift confirms that the Raman band at $4158 \mathrm{~cm}^{-1}$ results from hydrogen molecules in crystalline silicon. The band at around $1530 \mathrm{~cm}^{-1}$ is assigned to the stretching band of Si-D bonds in crystalline silicon. ${ }^{22}$

To exclude the possibility that the Raman signals of $\mathrm{H}_{2}$ arise from a very thin layer in the vicinity of the surface, which may be damaged by hydrogenation, we performed chemical etching of the surface layer with sequential rinses in $\mathrm{HNO}_{3}$ followed by HF. Even after etching away about 100 $\AA$, the vibrational Raman line of $4158 \mathrm{~cm}^{-1}$ showed no decrease in its intensity. We consequently conclude that hydrogen molecules exist not in damaged regions near the surface, but in bulk silicon crystal.

Figures 3 and 4 show the rotational and vibrational lines of $\mathrm{H}_{2}$ for the sample with $\mathrm{P}^{+}$implantation treated with various hydrogenation temperatures. The vibrational line was clearly observed at the hydrogenation temperatures between 180 and $500{ }^{\circ} \mathrm{C}$ while the rotational line was visible only between 300 and $400{ }^{\circ} \mathrm{C}$ because of overlap with the intense Raman bands of bulk silicon. The intensities of the rotational and vibrational lines are largest at hydrogenation temperature of $400{ }^{\circ} \mathrm{C}$. Figure 5 summarizes the intensity of the vibrational line as a function of hydrogenation temperature. The absence of the vibrational line for hydrogenation at $600{ }^{\circ} \mathrm{C}$ is consistent with the result of the SIMS experiments. ${ }^{26,27}$ The

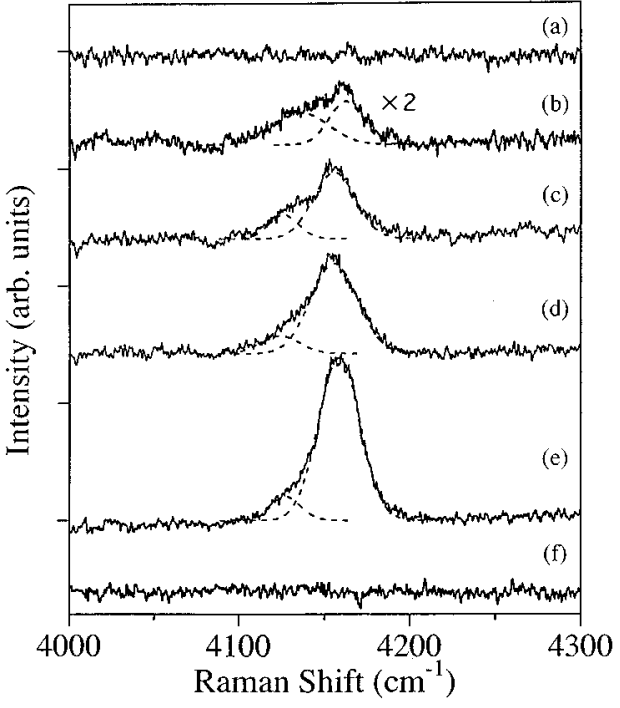

FIG. 4. The vibrational Raman line of $\mathrm{H}_{2}$ in crystalline silicon with $\mathrm{P}^{+}$implantation (a) before hydrogenation, and after hydrogenation at (b) $180{ }^{\circ} \mathrm{C}$, (c) $250{ }^{\circ} \mathrm{C}$, (d) $300{ }^{\circ} \mathrm{C}$, (e) $400{ }^{\circ} \mathrm{C}$, and (f) $600{ }^{\circ} \mathrm{C}$. The dashed lines are decomposed components using Gaussian shapes.

width of the vibrational line of $\mathrm{H}_{2}$ decreases with increasing hydrogenation temperature, while the Raman shift was almost constant at $4158 \pm 3 \mathrm{~cm}^{-1}$. Between the samples with and without $\mathrm{P}^{+}$implantation little difference was observed in the hydrogenation-temperature dependence of the intensity, the Raman shift, and the width.

Figures 6 and 7 show the Raman spectra of $\mathrm{Si}-\mathrm{H}$ stretching for the sample with and without $\mathrm{P}^{+}$implantation, respectively. The Raman band of Si-H was observed for hydrogenation between 100 and $500{ }^{\circ} \mathrm{C}$. The spectral shape of the $\mathrm{Si}-\mathrm{H}$ stretching changes with hydrogenation temperatures for the samples with $\mathrm{P}^{+}$implantation, whereas it is almost constant for the samples without $\mathrm{P}^{+}$implantation. The line shape for hydrogenation at $180{ }^{\circ} \mathrm{C}$ is particularly different; the Raman band for the samples without implantation has a peak at around $2100 \mathrm{~cm}^{-1}$ with a shoulder at about $2130 \mathrm{~cm}^{-1}$,

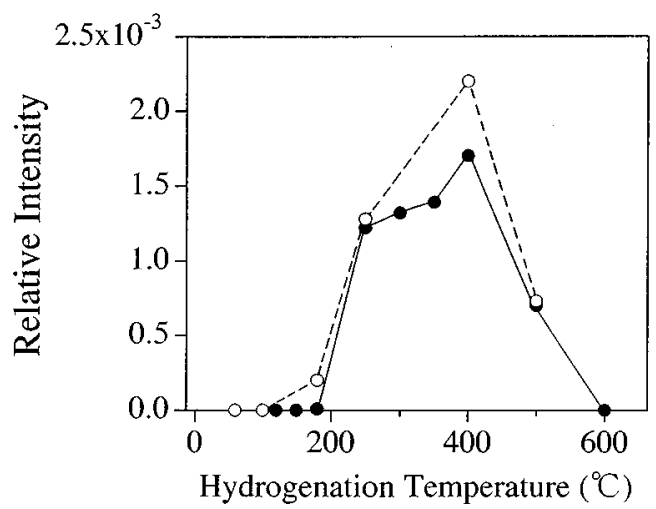

FIG. 5. The intensity of the vibrational Raman line of $\mathrm{H}_{2}$ as functions of the hydrogenation temperature. The closed and open circles indicate the results for the samples with and without $\mathrm{P}^{+}$ implantation, respectively. The Raman intensities are normalized by that of the optical-phonon line of silicon at $521 \mathrm{~cm}^{-1}$. 


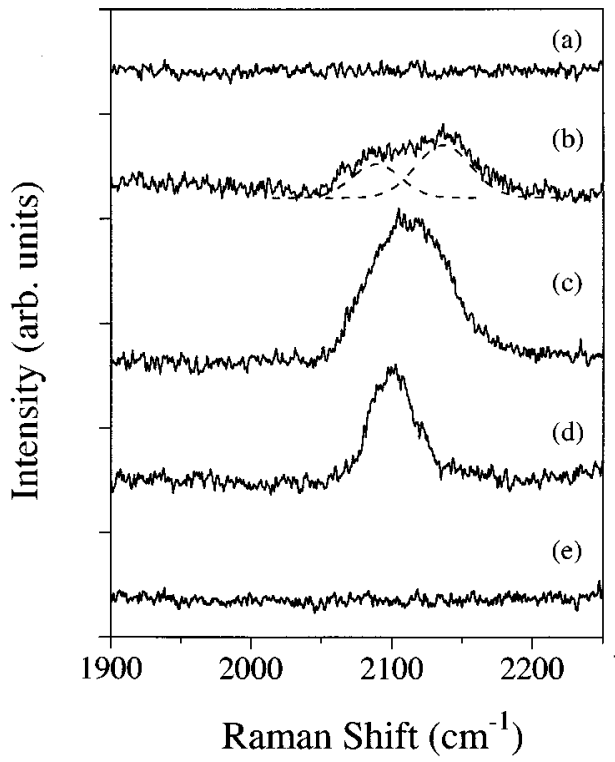

FIG. 6. Raman spectra of Si-H stretching for crystalline silicon with $\mathrm{P}^{+}$implantation (a) before hydrogenation, and after hydrogenation at (b) $180{ }^{\circ} \mathrm{C}$, (c) $250{ }^{\circ} \mathrm{C}$, (d) $400{ }^{\circ} \mathrm{C}$, and (e) $600{ }^{\circ} \mathrm{C}$. The dashed curves are decomposed components using Gaussian line shapes.

while for the samples with implantation treated at hydrogenation temperatures of $150-180{ }^{\circ} \mathrm{C}$ the peak is centered at around $2130 \mathrm{~cm}^{-1}$ with a shoulder peak at about $2100 \mathrm{~cm}^{-1}$. Figure 8 summarizes the intensity of the $\mathrm{Si}-\mathrm{H}$ stretching band as a function of the hydrogenation temperature. It has a maximum at $250{ }^{\circ} \mathrm{C}$ for the samples with and without $\mathrm{P}^{+}$implantation. The intensity maximum corresponds to the temperature above which $\{111\}$ platelets are unstable. $^{4,27}$

\section{DISCUSSION}

The intensity of the vibrational Raman line of $\mathrm{H}_{2}$ has a maximum at the hydrogenation temperature of $400{ }^{\circ} \mathrm{C}$, while

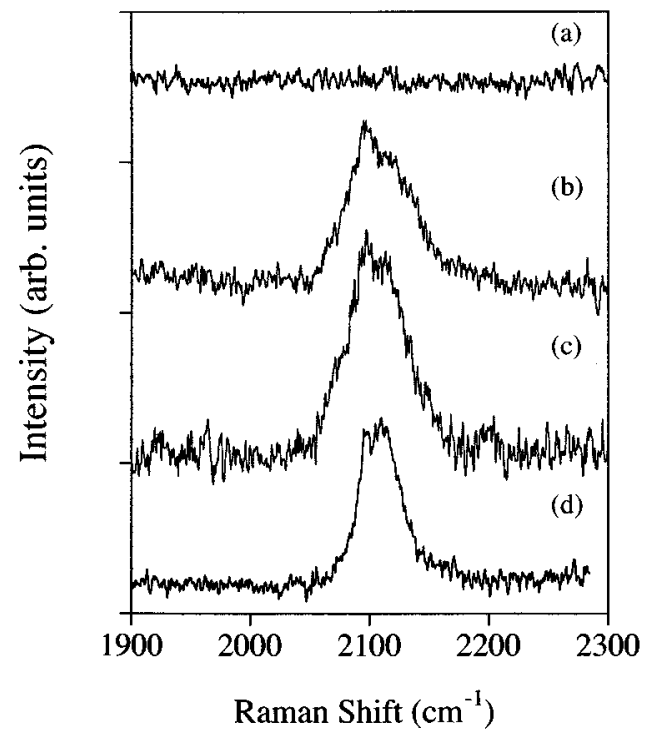

FIG. 7. Raman spectra of Si-H stretching for crystalline silicon without $\mathrm{P}^{+}$implantation (a) before hydrogenation, and after hydrogenation at (b) $180{ }^{\circ} \mathrm{C}$, (c) $250^{\circ} \mathrm{C}$, and (d) $400{ }^{\circ} \mathrm{C}$.

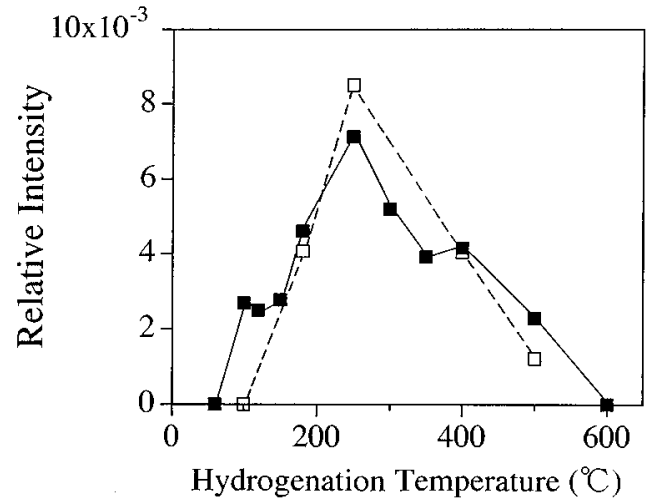

FIG. 8. The Raman intensity of the $\mathrm{Si}-\mathrm{H}$ stretching line as a function of the hydrogenation temperature. The closed and open squares indicate the results for the samples with and without $\mathrm{P}^{+}$ implantation, respectively. The Raman intensities are normalized by the Raman optical-phonon line of silicon at $521 \mathrm{~cm}^{-1}$.

that of the Si-H stretching line occurs at $250{ }^{\circ} \mathrm{C}$. The SIMS measurements show that the total amount of hydrogen introduced in silicon is greatest for hydrogenation at $400{ }^{\circ} \mathrm{C}$. The hydrogenation-temperature dependence of the formation of $\mathrm{H}_{2}$ and $\mathrm{Si}-\mathrm{H}$ is consistent with that of the electron spin resonance (ESR) linewidth of the donor and/or conduction electrons at $4.2 \mathrm{~K}$ for HAT samples. ${ }^{31}$ The ESR linewidth has two maxima at around 200 and $400{ }^{\circ} \mathrm{C}$. The maximum at $200{ }^{\circ} \mathrm{C}$ is explained by the hyperfine interaction between electrons and nuclear spin of a single $\mathrm{H}$ atom such as $\mathrm{H}$ atoms in $\mathrm{Si}-\mathrm{H}$ bonds, while that at $400{ }^{\circ} \mathrm{C}$ is predominantly by the interaction between electrons and nuclear spin of $\mathrm{H}_{2}$. The maximum at $400{ }^{\circ} \mathrm{C}$ showed an isotope effect between $\mathrm{H}$ and D. ${ }^{31}$ This shows that $\mathrm{H}_{2}$ does not exist in voids or bubbles, where the wave function of donor and/or conduction electrons would not penetrate deep enough, but in the interstitial site in crystalline silicon.

The vibrational line of $\mathrm{H}_{2}$ is very broad and asymmetric. We decomposed the spectra using two Gaussian line shapes, as shown with the dashed lines in Fig. 4. The two components have peaks at about 4160 and $4130 \mathrm{~cm}^{-1}$. The intensities of the two components are shown in Fig. 9 as a function of the hydrogenation temperature. The intensity of the component at $4160 \mathrm{~cm}^{-1}$, which is always much larger than

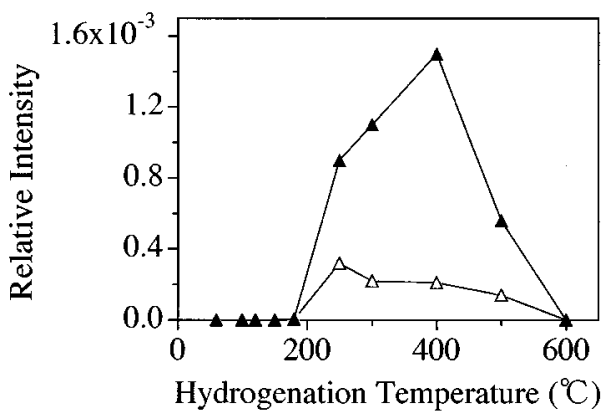

FIG. 9. The intensities of the components at $4130 \mathrm{~cm}^{-1}$ (open triangles) and $4160 \mathrm{~cm}^{-1}$ (closed triangles) of the sample with $\mathrm{P}^{+}$ implantation as a function of hydrogenation temperature. These intensities are normalized by the Raman optical-phonon line of silicon at $521 \mathrm{~cm}^{-1}$. 
the other component, has a maximum at $400{ }^{\circ} \mathrm{C}$, while the intensity of the component at $4130 \mathrm{~cm}^{-1}$ is largest at $250{ }^{\circ} \mathrm{C}$. The components are assigned to $\mathrm{H}_{2}$ in two different occupation sites in crystalline silicon. A tetrahedral interstitial $\left(T_{d}\right)$ site has been proposed as one of the occupation sites of $\mathrm{H}_{2}$ in crystalline silicon, according to recent theoretical calculations. ${ }^{10-15} \mathrm{We}$ attribute the component at $4160 \mathrm{~cm}^{-1}$, which is the more intense, to $\mathrm{H}_{2}$ in the $T_{d}$ site. The hydrogenation-temperature dependence of the intensity of the component at $4130 \mathrm{~cm}^{-1}$, especially the decrease above $250{ }^{\circ} \mathrm{C}$, is similar to that of the $\mathrm{Si}-\mathrm{H}$ stretching as shown in Fig. 8. Therefore, we tentatively, assigned the component at $4130 \mathrm{~cm}^{-1}$ to $\mathrm{H}_{2}$ in a distorted $T_{d}$ site where an $\mathrm{Si}-\mathrm{H}$ bond is located as the nearest neighbor.

Each component of the vibrational line of $\mathrm{H}_{2}$ after decomposition is still very broad compared with the vibrational line of gas, liquid, and solid $\mathrm{H}_{2} \cdot{ }^{28-30}$ The present Raman measurements have a spectral resolution of $0.2 \mathrm{~cm}^{-1}$, fine enough to distinguish the vibrational lines of para- and ortho$\mathrm{H}_{2}\left[Q_{1}(0)\right.$ and $\left.Q_{1}(1)\right]$ in gas or solid phase. Yet no fine structure due to para- and ortho- $\mathrm{H}_{2}$ is observed in the $Q_{1}$ vibrational line in the present study. The broadening of the vibrational line of $\mathrm{H}_{2}$ is too large to be explained by highpressure gaseous $\mathrm{H}_{2}$. The width of the vibrational Raman line of gaseous $\mathrm{H}_{2}$ at room temperature is no more than $3 \mathrm{~cm}^{-1}$ at a pressure of $2000 \mathrm{~atm},{ }^{29}$ which corresponds to the pressure of gaseous $\mathrm{H}_{2}$ trapped in microvoids in heavily hydrogenated amorphous silicon. ${ }^{16}$ On the other hand, for $\mathrm{H}_{2}$ dissolved in vitreous silica, the width of the vibrational line of $\mathrm{H}_{2}$ was about $20 \mathrm{~cm}^{-1}$ at room temperature and exhibited significant narrowing with decreasing measurement temperature. ${ }^{32}$ The temperature-dependent part of the width is explained in terms of motional broadening including rotational relaxation while the temperature-independent width obtained by the extrapolation to $0 \mathrm{~K}$ results from the inhomogeneous broadening. In the present study the width of the vibrational line of $\mathrm{H}_{2}$ in crystalline silicon does not change with the measurement temperature down to $90 \mathrm{~K}$. We therefore attribute the broadening of the vibrational line not to motional broadening but predominantly to inhomogeneous broadening. A plausible explanation for the inhomogeneous broadening is orientational effect. Recently, Nakamura and co-workers calculated the potential of a hydrogen molecule in a silicon cluster $\left(\mathrm{Si}_{10} \mathrm{H}_{16}\right)$ using the ab initio Hartree-Fock method. ${ }^{14,15}$ They found that the most stable configuration of a hydrogen molecule in the cluster is at the tetrahedral interstitial site, oriented along a $\langle 100\rangle$ direction with a bond length of $0.70 \AA$, about $0.04 \AA$ shorter than in gas phase. The vibrational frequency of the hydrogen molecule is calculated to be $4470 \mathrm{~cm}^{-1}$, which is in agreement with the present study. They also calculated the orientational effect on the vibrational energy of $\mathrm{H}_{2}$ at the $T_{d}$ site, and found that it has a distribution of about $30 \mathrm{~cm}^{-1}$. This value is comparable to the width of the vibrational Raman line of $\mathrm{H}_{2}$ in crystalline silicon observed in the present study. Thus the orientation of $\mathrm{H}_{2}$ is a plausible origin of the inhomogeneous broadening of the vibrational Raman line of $\mathrm{H}_{2}$ in crystalline silicon.

The Raman spectra of $\mathrm{Si}-\mathrm{H}$ stretching for the HAT$180^{\circ} \mathrm{C}$ sample is asymmetric, consisting of two components at 2100 and $2130 \mathrm{~cm}^{-1}$. Deak et al. calculated the structure of hydrogen platelets using the self-consistent semiempirical MINDO/3 Hamiltonian, in which pairs of hydrogen atoms saturate the broken bonds between two adjacent $\mathrm{Si}$ atoms at the (111) surface. ${ }^{5}$ According to their calculation, Si-H stretching has energies of 2095 and $2122 \mathrm{~cm}^{-1}$. Heyman et al. reported local vibrational modes of hydrogen-induced platelets at 2065, 2095, and $2125 \mathrm{~cm}^{-1}$ in crystalline silicon after plasma hydrogenation. ${ }^{6}$ The peak wave numbers of the two components in the present study are in agreement with the theoretical and experimental $\left(2095\right.$ and $\left.2125 \mathrm{~cm}^{-1}\right)$ values. However, the thermal stability of the two peaks is different in the present study: the peak at $2100 \mathrm{~cm}^{-1}$ persists for hydrogenation up to $500{ }^{\circ} \mathrm{C}$, while that at $2130 \mathrm{~cm}^{-1}$ vanishes for a hydrogenation temperature above $250{ }^{\circ} \mathrm{C}$. We attribute the peak at $2130 \mathrm{~cm}^{-1}$ to the $\mathrm{Si}-\mathrm{H}$ bonds in platelets and $2100 \mathrm{~cm}^{-1}$ to isolated $\mathrm{Si}-\mathrm{H}$ bonds other than platelets, since a TEM study showed that platelets are not stable above $250{ }^{\circ} \mathrm{C} .{ }^{4}$ The assignment is consistent with the intensity for the sample with $\mathrm{P}^{+}$implantation being larger than that for the sample without $\mathrm{P}^{+}$implantation, since platelets are known to be formed preferentially in heavily doped $n$-type silicon. ${ }^{1}$ The higher wave number of the peak may be a consequence of the strains and stress given to the $\mathrm{Si}-\mathrm{H}$ bonds in $\{111\}$ platelets.

\section{CONCLUSIONS}

We have confirmed the existence of hydrogen molecules in crystalline silicon treated with hydrogen atoms at hydrogenation temperatures between 180 and $500{ }^{\circ} \mathrm{C}$ by means of Raman measurements. The vibrational and rotational Raman lines of hydrogen molecules in crystalline silicon are observed at 4158 and $590 \mathrm{~cm}^{-1}$, respectively. The vibrational Raman line of deuterium molecules in crystalline silicon is observed at around $2990 \mathrm{~cm}^{-1}$. The intensity of the vibrational Raman line of $\mathrm{H}_{2}$ has a maximum for a hydrogenation temperature of $400{ }^{\circ} \mathrm{C}$. The formation efficiency of hydrogen molecules is similar for samples with or without $\mathrm{P}^{+}$implantation. The broad and asymmetric Raman spectrum of $\mathrm{H}_{2}$ suggests that the configurations for the hydrogen molecules are not unique in crystalline silicon. We decomposed the Raman spectrum into two components. The component at about $4160 \mathrm{~cm}^{-1}$ is assigned to $\mathrm{H}_{2}$ in the tetrahedral interstitial site in crystalline silicon, which was predicted by the theoretical calculations, and the component at about $4130 \mathrm{~cm}^{-1}$ tentatively to $\mathrm{H}_{2}$ in the $T_{d}$ site having an Si-H bond as the nearest neighbor. The Raman spectrum of Si-H stretching was observed for hydrogenation temperatures between 100 and $500{ }^{\circ} \mathrm{C}$. Its intensity has a maximum at $250{ }^{\circ} \mathrm{C}$. The Raman peak at $2130 \mathrm{~cm}^{-1}$, observed for the samples treated with hydrogen atoms at the substrate temperatures between 150 and $250{ }^{\circ} \mathrm{C}$, is attributed to $\mathrm{Si}-\mathrm{H}$ in $\{111\}$ platelets.

\section{ACKNOWLEDGMENTS}

We would like to thank Dr. I. Sakaguchi for performing SIMS measurement. We also thank Dr. R. Bastasz for his critical reading of the manuscript and fruitful comments. This work is a part of a research contract from the NEDO. 
${ }^{1}$ See, Hydrogen in Semiconductors, edited by J. I. Pankove and N. M. Johnson, Semiconductors and Semimetals Vol. 34 (Academic, New York, 1991).

${ }^{2}$ K. Bergman, M. Stavola, S. J. Pearton, and J. Lopata, Phys. Rev. B 37, 2770 (1988).

${ }^{3}$ C. G. Van de Walle, Y. Bar-Yam, and S. T. Pantelides, Phys. Rev. Lett. 60, 2761 (1988).

${ }^{4}$ N. M. Johnson, F. A. Ponce, R. A. Street, and R. J. Nemanich, Phys. Rev. B 35, 4166 (1987).

${ }^{5}$ P. Deak, C. R. Ortiz, L. C. Snyder, and J. W. Corbett, Physica B 170, 233 (1991).

${ }^{6}$ J. N. Heyman, J. W. Ager, E. E. Haller, N. M. Johnson, J. Walker, and C. M. Doland, Phys. Rev. B 45, 13363 (1992).

${ }^{7}$ S. B. Zhang and W. B. Jackson, Phys. Rev. B 43, 12142 (1991).

${ }^{8}$ S. Muto, S. Takeda, and M. Hirata, J. Appl. Phys. 70, 3505 (1991)

${ }^{9}$ K. J. Chang and D. J. Chadi, Phys. Rev. Lett. 60, 1422 (1988).

${ }^{10}$ K. J. Chang and D. J. Chadi, Phys. Rev. B 40, 11644 (1989).

${ }^{11}$ D. J. Chadi and C. H. Park, Phys. Rev. B 52, 8877 (1995).

${ }^{12}$ C. G. Van. de Walle, P. J. H. Denteneer, Y. Bar-Yam, and S. T. Pantelides, Phys. Rev. B 39, 10791 (1989).

${ }^{13}$ C. G. Van. de Walle, Phys. Rev. B 49, 4579 (1994).

${ }^{14}$ K. G. Nakamura, K. Ishioka, M. Kitajima, and K. Murakami, Solid State Commun. 101, 735 (1997).

${ }^{15}$ K. G. Nakamura and M. Kitajima, Jpn. J. Appl. Phys., Part 1 36, 2004 (1997).

${ }^{16}$ Y. J. Chabal and C. K. N. Patel, Phys. Rev. Lett. 53, 210 (1984).

${ }^{17}$ J. B. Boyce and M. Stutzmann, Phys. Rev. Lett. 54, 562 (1985).

${ }^{18}$ M. Stutzmann, W. Beyer, L. Tapfer, and C. P. Herrero, Physica B 170, 240 (1991).

${ }^{19}$ N. M. Johnson and C. Herring, Phys. Rev. B 38, 1581 (1988).
${ }^{20}$ P. Stallinga, T. Gregorkiewicz, C. A. J. Ammerlaan, and Yu. V. Gorelkinskii, Phys. Rev. Lett. 71, 117 (1993).

${ }^{21}$ K. L. Brower, S. M. Myers, A. H. Edwars, N. M. Johnson, C. G. Van de Walle, and E. H. Poindexter, Phys. Rev. Lett. 73, 1456 (1994).

${ }^{22}$ K. Murakami, N. Fukata, S. Sasaki, K. Ishioka, M. Kitajima, S. Fujimura, J. Kikuchi, and H. Haneda, Phys. Rev. Lett. 77, 3161 (1996).

${ }^{23}$ N. Fukata, S. Sasaki, K. Murakami, K. Ishioka, M. Kitajima, S. Fujimura, J. Kikuchi, and H. Haneda, Jpn. J. Appl. Phys. Lett. 35, L1069 (1996).

${ }^{24}$ K. Ishioka, K. G. Nakamura, M. Kitajima, N. Fukata, S. Sasaki, K. Murakami, J. Kikuchi, S. Fujimura, and H. Haneda, Appl. Surf. Sci. 117/118, 37 (1997).

${ }^{25}$ J. Vetterhoffer, J. Wagner, and J. Weber, Phys. Rev. Lett. 77, 5409 (1996).

${ }^{26}$ N. Fukata, S. Fujimura, and K. Murakami, Mater. Sci. Forum 196, 873 (1995).

${ }^{27}$ N. Fukata, S. Sasaki, S. Fujimura, H. Haneda, and K. Murakami, Jpn. J. Appl. Phys., Part 1 35, 3937 (1996).

${ }^{28}$ B. P. Stoicheff, Can. J. Phys. 35, 730 (1957).

${ }^{29}$ A. D. May, V. Degen, J. C. Stryland, and H. L. Welsh, Can. J. Phys. 39, 1769 (1961).

${ }^{30}$ S. S. Bhatnagar, E. J. Allin, and H. L. Welsh, Can. J. Phys. 40, 9 (1962).

${ }^{31}$ K. Murakami, N. Fukata, S. Sasaki, K. Ishioka, M. Kitajima, S. Fujimura, J. Kikuchi, and H. Haneda, in Proceedings of the Material Research Society No. 442 (Materials Research Society, Pittsburgh, 1997), p. 269.

${ }^{32}$ C. M. Hartwig and J. Vitko, Phys. Rev. B 18, 3006 (1978). 